\title{
artículos
}

\section{La Policromía de Andrés de Carvajal}

\author{
Beatriz Prado Campos
}

Investigadora vinculada a la UMA

\section{RESUMEN}

En este artículo se exponen las claves para conocer y reconocer la policromía de las esculturas del insigne artista antequerano Andrés de Carvajal, estudiada desde el punto de vista de su decoración ornamental, método de ejecución para su creación y su relación a su vez, con los modelos iconográficos que representan. Con todo ello, queda manifiesto el estilo personal y característico del artista, siendo el aspecto polícromo uno de los fundamentos para la atribución de sus obras.

PALABRAS CLAVE: policromía/ ornamentación/ motivo decorativo/ técnica de ejecución/ escultura/ Andrés de Carvajal.

\section{Andrés de Carvajal's Polychrome}

\section{ABSTRACT}

This article describes the keys to know and recognize the polychrome of sculpture of the notable artist from Antequera, Andrés de Carvajal, studied under the point of view of ornamental decoration, implementation method for creation and related with the iconographic models of representation. With all this, it is evident and distinctive a personal style of the artist, being the aspects polychrome, one of these fundaments to attribute your owns work of sculpture.

KEY WORDS: polychrome/ornamentation/ decorative motif/ execution technique/ sculpture/ Andrés de Carvajal.

La policromía o "piel" de una escultura es aquella que aún siendo el primer aspecto que se percibe de la misma, se relega a un segundo o tercer plano en detrimento de su talla, modelado o autoría. Con este artículo, se pone de manifiesto cuan interesante es el estudio de las policromías, hasta el punto de permitir reconocer aspectos estilísticos comunes en un mismo artista e identificarlos en sus obras cuando éste es analizado dentro de un contexto concreto.

La figura elegida para estudiar y analizar las características de sus policromías es el insigne escultor antequerano ${ }^{1}$ Andrés de Carvajal y Campos; en su reconocida producción en la ciudad de Antequera, y máximo exponente de la policromía barroca

*PRADO CAMPOS, Beatriz: "La Policromía de Andrés de Carvajal", en Boletín de Arte n 32-33, Departamento de Historia del Arte, Universidad de Málaga, 2011-2012, págs. 207-221. Fecha de recepción: Mayo de 2012.

1 Andrés de Carvajal y Campos es almeriense de nacimiento (Fondón, 31 de julio de 1709), aunque se reconoce como hijo propio de la ciudad de Antequera, debido a que se afincó en ella desde 1740, donde fundó taller y desarrolló la mayor parte de su obra artística escultórica religiosa. Viniendo de una familia acomodada, de tradición paterna del gremio de sastres, se diferenció de sus hermanos por buscar su propio camino en el gremio de la escultura polícroma, formándose en el Taller de Diego de Mora en Granada. Establecido en Antequera contrajo matrimonio con la hija del escribano Miguel Francisco de Talavera, Magdalena Talavera y Cueto, con quien tuvo un hijo, Miguel María, también escultor y pintor, aunque por el momento no se le atribuye ninguna producción artística, probablemente debido a la sombra que su padre proyecta. 
Antequerana junto a la familia de los Márquez. Este artículo nace como resultado de una profunda investigación acerca de los motivos ornamentales y técnicas de ejecución desarrollados en las policromías antequeranas aplicadas en la escultura exenta (un total de 135 esculturas), que se materializó en una tesis doctoral².

Las policromías de Carvajal se caracterizan por tener un estilo polícromo bien definido, sin excesos técnicos, con motivos decorativos de sencillo trazado, de creación propia y singulares peculiaridades, que definen en su conjunto un estilo personal, que de alguna manera ha calado profundamente en el ámbito artístico-cultural antequerano. Su personalidad artística estriba fundamentalmente en la maestría con la que desarrolla el programa polícromo, conjugando los motivos decorativos con la decoración de fondo de las indumentarias, a la vez que establece una metodología de ejecución precisa y concreta y que aplica según la iconografía del personaje representado. Por todo ello el artículo se divide en tres grandes apartados: A. motivos decorativos, B. decoración de los fondos de las indumentarias y C. iconografía.

\section{A. Motivos decorativos.}

Uno de los aspectos que definen y caracterizan el estilo polícromo de Andrés de Carvajal, son los motivos decorativos que emplea en la decoración de las indumentarias de sus esculturas. Se aprecian cualidades formales relacionadas con el diseño, técnica de ejecución y naturaleza, que permiten reconocer sus obras y su estilo polícromo.

Los motivos decorativos que emplea se caracterizan por presentar en su conjunto, diseños de trazado sencillo en los cuales las líneas de contorno están bien definidas y cierran los motivos, reconociendo las formas fácilmente, a excepción de aquellos motivos que emplean la misma técnica que en la decoración del fondo y es entonces cuando resulta más confusa su percepción visual.

Las técnicas de ejecución con las que juega para la elaboración de los motivos son las zonas de reserva de metal, tanto oro como plata, generalmente decoradas con punzonados que rellenan o dibujan el motivo, y trazos a pincel para siluetear contornos, o tintas planas superpuestas que rellenan el motivo y crean trasparencias que van generando el efecto de volumen.

2 PRADO CAMPOS, Beatriz. Estudio Comparativo de la Policromía Aplicada a la Escultura Exenta en Madera de los Siglos XV al XVIII en Antequera, Málaga: Motivos Ornamentales y Técnicas de Ejecución. Sevilla, Servicio de publicaciones de la Universidad de Sevilla, 2011. 


\begin{tabular}{|c|c|}
\hline 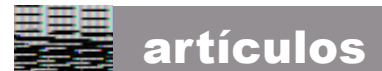 & La Policromía de Andrés de Carvajal \\
\hline
\end{tabular}

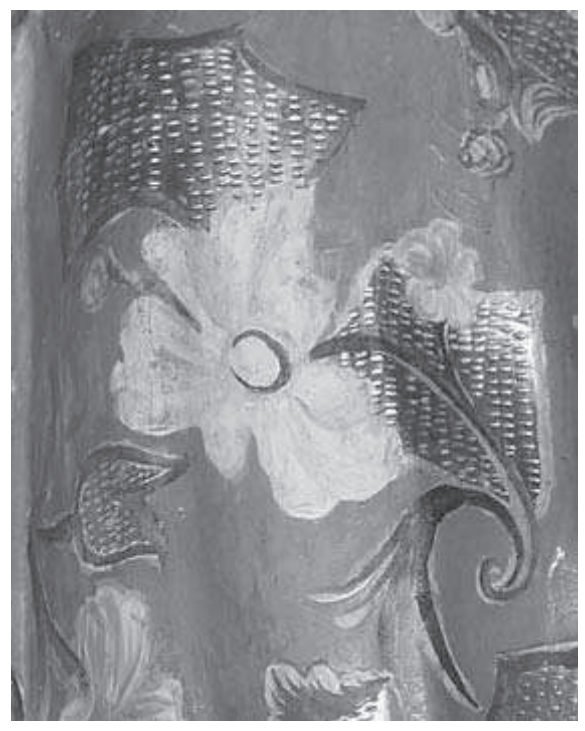

La naturaleza de los motivos a los que recurre Carvajal para sus ornamentaciones está inspirada en la flora de su entorno, recreando motivos de naturaleza floral y vegetal. Destaca la creación del motivo denominado "forma poligonal de aristas vivas" que es exclusivo y seña de su mano como artista. Los principales motivos ornamentales hallados en sus policromías son los siguientes:

Lazos y guirnaldas: son elementos decorativos con formas ondulantes y aparentemente desordenadas, que distribuyen el espacio compositivo polícromo, insertándose alrededor de ellos otros motivos decorativos, generalmente de naturaleza floral. En cuanto a técnica de ejecución, los presenta en oro ${ }^{3}$ y plata ${ }^{4}$ pulida con decoraciones punzonadas, o bien, policromados ${ }^{5}$, y siempre, todos ellos presentan los contornos delimitados con trazos finos a pincel.

[1] Formas poligonales de aristas vivas: este modelo decorativo es completamente exclusivo de su manufactura, ya que no se han hallado en las obras de otros artistas. Presentan formas planas imitando polígonos, en los que las líneas de contorno son ligeramente curvas, generalmente inclinadas hacía el epicentro, pero a su vez cortantes. Técnicamente son trabajos en oro pulido con decoraciones de huellas rectangulares punzonadas, y el perímetro silueteado con líneas a pincel. Es un elemento secundario que complementa a otro de mayor relevancia de naturaleza floral.

3 Escultura de Santiago de la Iglesia de Santiago (40-ISAR01E1).

4 Esculturas: Virgen del Refugio de la Iglesia Convento de Nuestra Señora de los Remedios (57-ICNSRR02E1B)

y Santa Eufemia de la Iglesia Convento de Santa Eufemia (43-ICSER03E1B).

5 Escultura de San José de la Iglesia Convento de la Trinidad (107-ICTR02E1) 


\begin{tabular}{|c|c|}
\hline 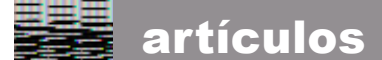 & Beatriz Prado Campos \\
\hline
\end{tabular}
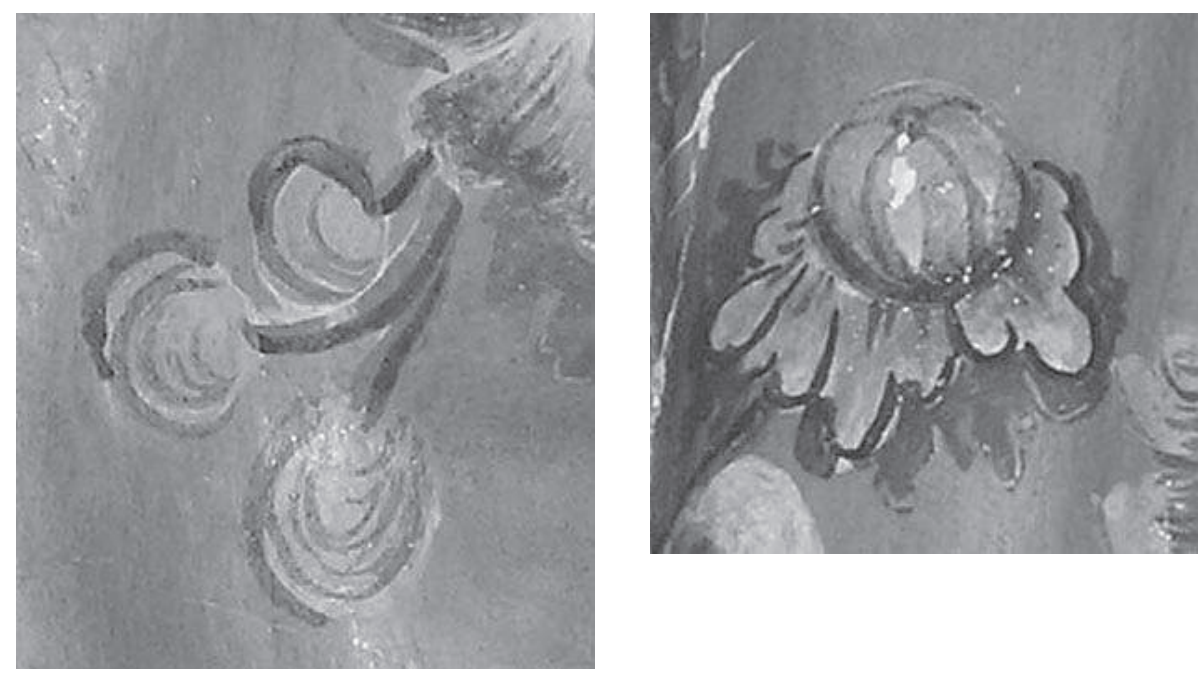

[2] Bulbo floral: este tipo de motivo, al igual que el anterior, es exclusivo de Carvajal. Su diseño básico consta de una forma redondeada central, de la que nacen un conjunto de hojas en la parte inferior con un pequeño tallo fino y alargado. Generalmente la visión del motivo es de perfil o tres cuartos, y las técnicas que se emplean, varían de unos casos a otros, predominando la técnica a pincel que rellena el motivo a base de una superficie plana, silueteándose con trazos más oscuros el dibujo.

[3] Racimo de fruto de olivo: se caracteriza por presentar varios pequeños y finos tallos unidos, que terminan en una forma esférica que simula un fruto. Aparecen agrupados en dos o tres tallos con fruto, o bien individualmente. La técnica más utilizada para realizar el fruto es a pincel, superponiendo capas que van creando la forma más o menos esférica, también se han observado frutos realizados a base de reservas de oro pulido punzonadas, y todos ellos, siempre silueteados con líneas a pincel. Los tallos se trabajan con finas líneas a pincel, combinando trazos claros y oscuros.

Florales: los motivos de naturaleza floral son los más recurrentes tanto en las policromías del artista como en la policromía antequerana en su conjunto. La variedad en las formas es muy amplia y variada, así como la distribución de los diferentes planos de importancia visual de las distintas partes del ornamento. Destacan los tratamientos técnicos, en donde reside la grandeza del artista, ya que combina distintos métodos de una forma singular que al observarlos hacen 


\begin{tabular}{|c|c|}
\hline 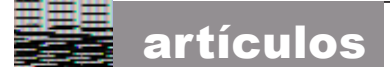 & La Policromía de Andrés de Carvajal \\
\hline
\end{tabular}

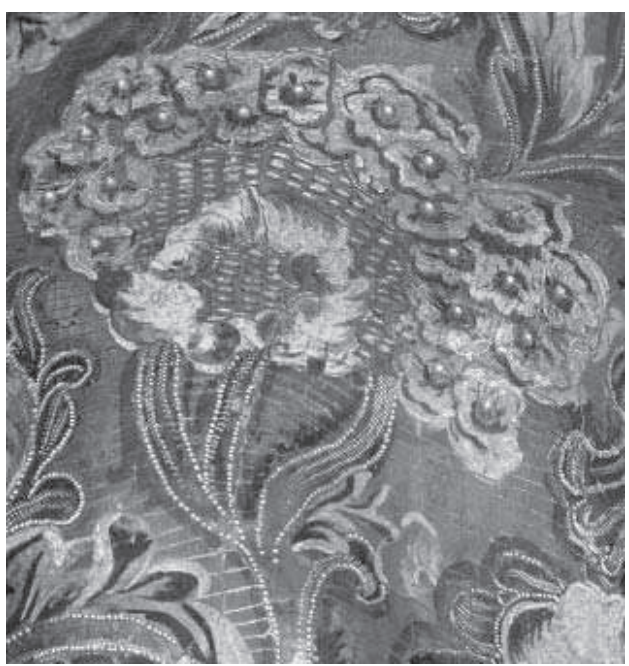

reconocible su estilo. Las técnicas que emplea son tres: a pincel, reserva de oro y punzonados. La primera, a pincel, la utiliza para crear el motivo en todo su conjunto, o bien, realiza una parte de él con esta técnica y lo complementa con las otras, quedando en un plano principal o secundario. La segunda técnica, reserva de oro o plata, aparecen como parte del motivo, constituyendo la zona central o bien acompañando al motivo principal. Y en la tercera técnica, los punzonados, siempre van ligados a las zonas de metal, constituyendo la decoración principal de los mismos. Aunque la función más común, es la de relleno de toda la superficie de reserva, cuando a motivos se refiere, también cumplen la función de siluetear y trazar contornos o refuerzos del dibujo del motivo decorativo.

[4] Ramilletes: el motivo parte de un mismo tallo que se ramifica y remata con distintos elementos ornamentales, las ramificaciones y remates varían de unos motivos a otros. Al igual que en los motivos florales, los procedimientos técnicos son: realizado exclusivamente a pincel, o combinado con elementos en reserva de oro o plata punzonados.

Red: estos motivos son característicos de las policromías barrocas antequeranas de tipo tridimensional ${ }^{6}$, y no especialmente de este autor, pero se han observado en una de sus obras ${ }^{7}$. El diseño del motivo se configura a partir de una forma poligonal de aristas vivas, en las que se distribuye el espacio en forma

6 PRADO CAMPOS, Beatriz. Estudio Comparativo de la Policromía Aplicada a la Escultura Exenta en Madera de los Siglos XV al XVIII en Antequera, Málaga: Motivos Ornamentales y Técnicas de Ejecución. Sevilla, Servicio de publicaciones de la Universidad de Sevilla, 2011. Pág. 365 a 371.

7 Escultura de San José de la Iglesia de la Encarnación (111-ICER02E1). 
de red cuadrada dispuesta en diagonal. El entramado de la red se realiza a partir de líneas finas a pincel y el interior de los escaques se decora con motivos florales.

Panal: es un caso único, puesto que solo se ha observado en una escultura ${ }^{8}$. El diseño del motivo está formado con una especie de óvalo de color blanco, en el que una línea azul va ascendiendo horizontalmente, rematado con una flor, también realizada a pincel.

Hojas: son motivos vegetales independientes en forma de hojas escamadas agrupadas alrededor de un mismo tallo. Se realizan en plata pulida con remates a pincel, empleando una gama de colores grisáceos y azulados.

\section{B. Decoración de los fondos de LAS indumentaRias.}

Cada uno de los ropajes que recrean la indumentaria de una escultura, están ornamentados por motivos decorativos que aparecen en un primer plano visual respecto a un fondo. Dicho fondo, a su vez presenta un determinado proceso técnico de ejecución. Si ese proceso se reitera en el contexto de un conjunto de obras, estamos ante una metodología de ejecución particular, como es el caso que nos ocupa del artista Andrés de Carvajal.

El escultor desarrolla tres tipos de métodos de ejecución que aplica en la construcción de las policromías de sus obras, y nos permiten reconocerlas y atribuirlas. Son los siguientes:

Método 1: motivos decorativos a pincel aplicados sobre fondo de oro decorado con punzonados.

Una parte de la indumentaria de la escultura (túnica o manto, cara exterior) está realizada a partir de láminas de metal dorado pulidas, aplicadas directamente sobre una capa previa de bol. Presentan la singularidad, de que posteriormente no se recubre dicha superficie con ninguna otra capa de color que impida la observación del oro, dejándolo completamente a la vista. De esta forma, el brillo del oro pulido se alterna con zonas mates producidas por los rehundimientos practicados en forma de incisiones punzonadas con huellas de tipo rectangular embotada, recubriendo íntegramente la superficie metálica. Estos fondos suelen ir ornamentados con motivos decorativos tratados principalmente con una técnica a pincel. [5] [6]

8 Escultura de Santa Eufemia procedente de la Iglesia Convento de Santa Eufemia (43-ICSER03E1B). 


\begin{tabular}{|c|c|}
\hline 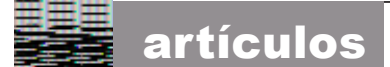 & La Policromía de Andrés de Carvajal \\
\hline
\end{tabular}
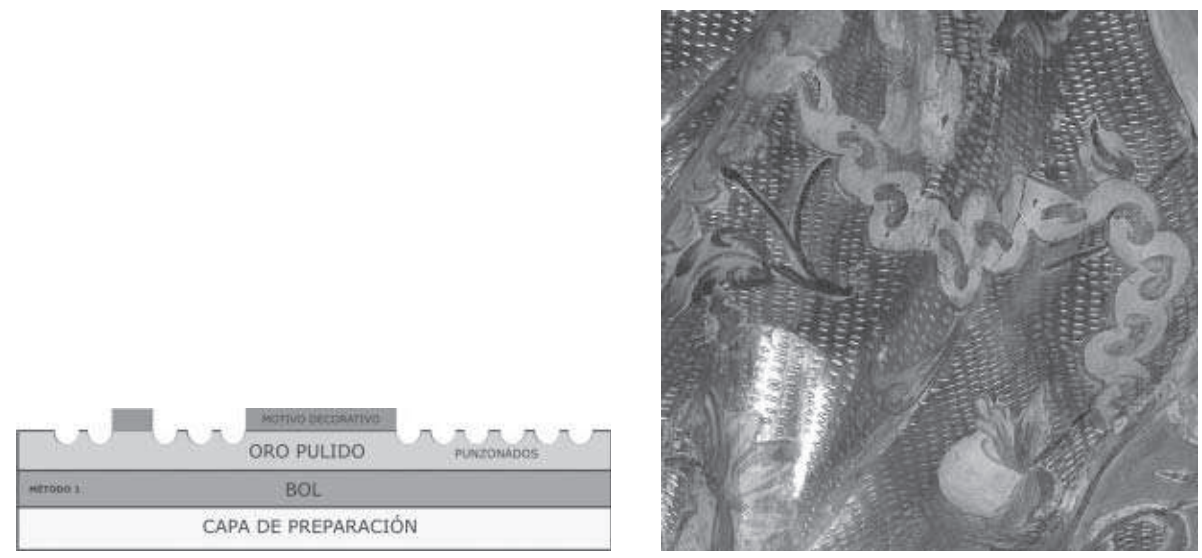

Método 2: motivos decorativos en reserva de oro y a pincel sobre superficie dorada parcialmente y policromada sin decoración.

La indumentaria de la escultura (túnica o manto, cara exterior) está configurada partiendo de una capa de color de fondo aplicada directamente sobre la capa de bol, sin existir una capa intermedia de oro, salvo zonas metálicas (oro o plata) dispuestas parcialmente sobre el conjunto de la superficie, y que serán destinadas a la creación de los motivos decorativos que la ornamenten. Esta policromía monocromática, aparece sin ningún tipo de decoración esgrafiada o punzonada, con un aspecto sustancialmente mate y superficie ligeramente rugosa, a diferencia del aspecto que ofrecen los fondos de las indumentarias ejecutadas técnicamente con el método 1. Los motivos decorativos que recubren estos fondos, están realizados combinando zonas tratadas a pincel y zonas de reserva de oro o plata, generalmente decoradas a su vez con punzonados en forma de huellas rectangulares embotadas. [7] [8]

Método 3: motivos decorativos en reserva de oro y a pincel sobre superficie dorada íntegramente y policromada con decoración.

De los tres métodos que se han verificado, éste es el más complejo y completo en cuanto a técnica, ejecución y riqueza ornamental, ya que en él se combinan los dos métodos anteriores y se introducen nuevos elementos.

En este método, la zona de indumentaria a decorar (túnica o manto, cara exterior) está realizada a partir de una superficie dorada y pulida íntegramente, previa capa de bol. Sobre ella, se aplica una capa de color generalizada reservando determinadas zonas de oro destinadas a configurar los motivos decorativos. Estos fondos policromados en un único tono, presentan decoraciones esgrafiadas con 


\begin{tabular}{|c|c|}
\hline 㭋琶 articulos & Beatriz Prado Campos \\
\hline
\end{tabular}
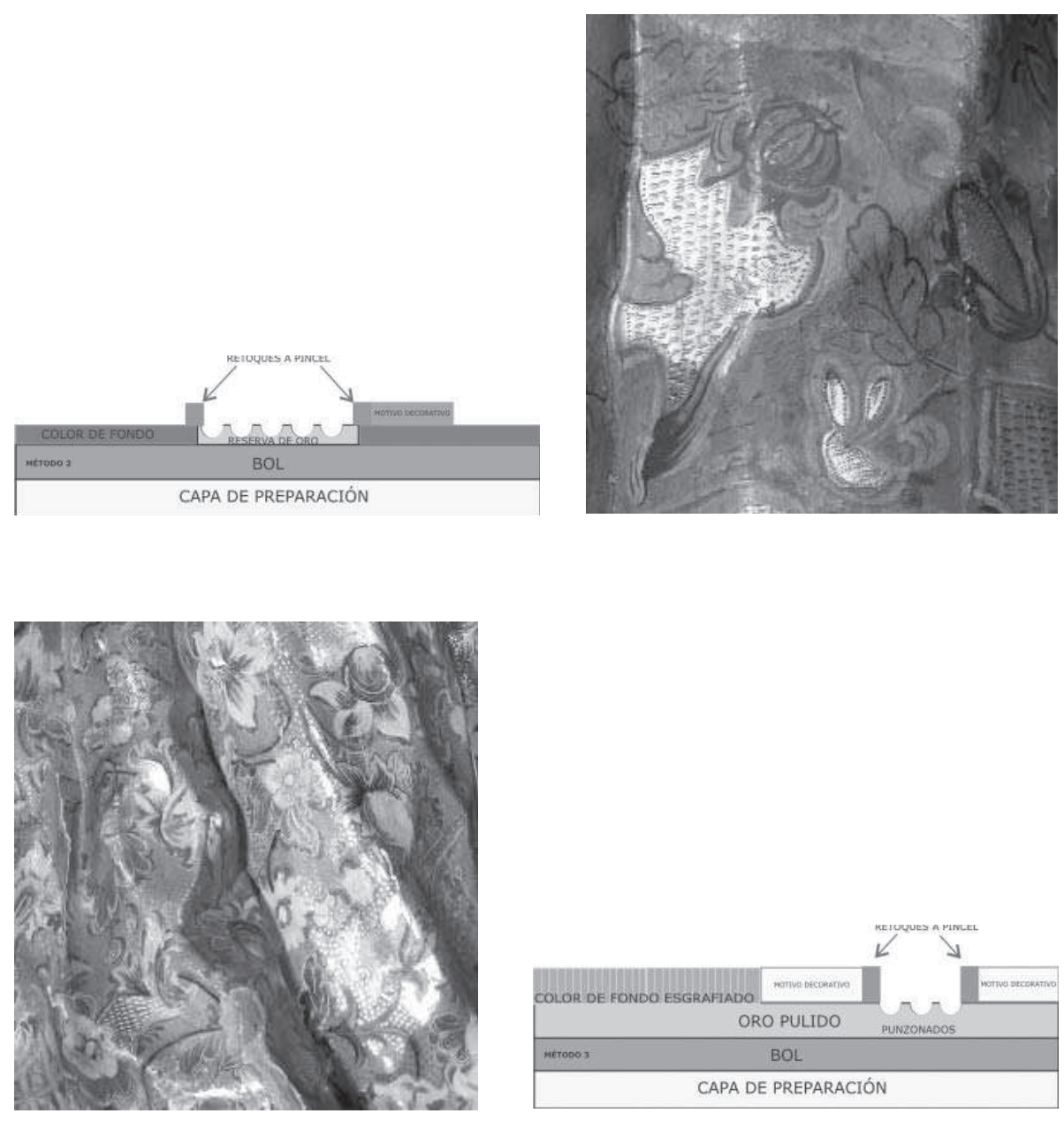

huellas generalmente rayadas o moteadas, que a su vez dan a la policromía un aspecto más lustroso y brillante con respecto al efecto hallado en las policromías del método 2. Los motivos decorativos, siguiendo el estilo del artista, se basan en la combinación de zonas en reserva de oro decoradas con punzonados; en este punto los tipos de huellas son más variados que en los casos anteriores, combinados con zonas trabajadas a pincel. Estas policromías son más ricas en cuanto a efectos ópticos debido a la variedad de huellas que mezcla e incorpora, así como por la alternancia de motivos en reserva de plata con los ya mencionados de oro. [9] [10] 


\begin{tabular}{|c|c|}
\hline 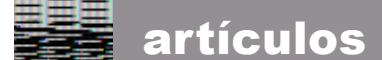 & La Policromía de Andrés de Carvajal \\
\hline
\end{tabular}

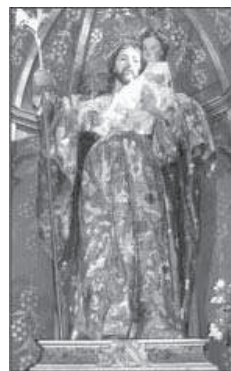

106-ICSER01E1

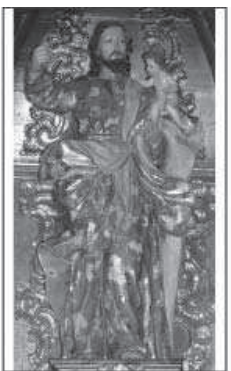

107-ICTR02E1

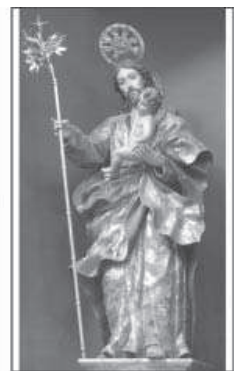

109-ICPR01E1

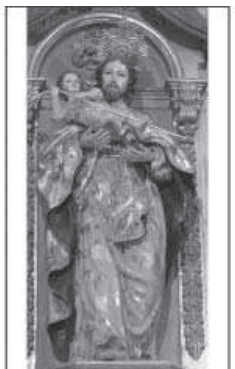

112-ICSSR03E1A

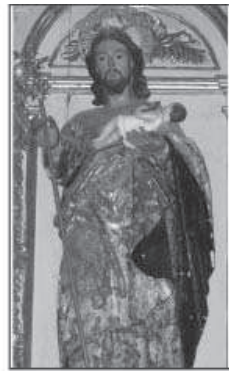

124-INSLR01E1

C. ICONOGRAFÍA.

Una vez conocidos y analizados los métodos de ejecución que Andrés de Carvajal emplea para la realización de sus obras, se ha podido constatar una relación directa entre la función iconográfica de los personajes representados y el procedimiento polícromo y programa decorativo de las vestimentas.

Iconográficamente, la obra de Carvajal se materializa mayoritariamente en la figura masculina frente a la femenina, destacando como primer modelo iconográfico característico del autor, las representaciones del Padre de Dios en la Tierra, San José, que constituye a su vez, un modelo iconográfico y plástico muy recurrente en la escultura barroca antequerana. El segundo modelo iconográfico representa una serie de santos, obras de segundo orden en su mayoría, y consideradas como obras de taller, y el tercer modelo iconográfico dedicado a la representación femenina, con iconografías de gran calado en el ámbito antequerano, como la Virgen y Santa Eufemia, patrona del municipio.

\section{SAN JOSÉ: PRIMER MODELO ICONOGRÁFICO.}

La iconografía de San José a manos de este escultor está representada por un conjunto de ocho esculturas procedentes de distintas iglesias de Antequera. Se ha incluido dentro de este grupo iconográfico una excepción, la representación del Apóstol Santiago de la Iglesia de su nombre, por presentar concordancias estilísticas y formales similares, desarrollando el mismo procedimiento técnico que el resto de las obras.

Las indumentarias que portan estas esculturas están compuestas fundamentalmente por túnica y manto. Analizando y comparando detenidamente 
dichos ropajes, se han observado características técnicas comunes entre ellos, en cuanto a gama cromática, métodos de ejecución, naturaleza y diseño de los motivos decorativos, entre otros.

Si nos centramos en la decoración de las túnicas, el primer aspecto en común que presentan todas ellas es, la utilización de un tono base monocromático azul-celeste, como única paleta de color que las recubre de forma homogénea y plana. En cuanto a procedimiento técnico de ejecución, se alternan dos métodos:

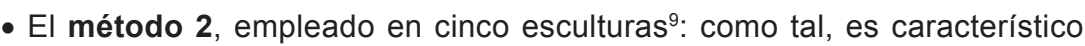
de este método el generar una superficie más plana y mate que los otros métodos conocidos de Carvajal, ya que el oro solo se suscribe a los motivos decorativos, encontrándose aplicado de forma parcial en el conjunto de la superficie de las túnicas. Los motivos decorativos empleados alternan formas poligonales de aristas vivas y flores realizadas a partir de la superposición de capas de color. Las túnicas están rematadas por cenefas decoradas con oro pulido punzonado, presentando diseños de cintas ondulantes y en zig-zag. [11]

- El método 3, empleado en sólo dos esculturas ${ }^{10}$ : a diferencia de las anteriores, éstas presentan unas túnicas más ricas tanto en su decoración como en el aspecto óptico determinado por el brillo que refleja el oro aplicado en toda la superficie de las túnicas. La presencia de motivos decorativos es muy destacada ocupando prácticamente toda la superficie y distribuyéndose de forma ordenada repitiendo un mismo módulo. El equilibrio entre zonas de oro y a pincel es constante, y se unen ambos para formar la unidad de la decoración. En la imagen de San José de la Iglesia de los Remedios, destaca la presencia de zonas plateadas pulidas incluidas dentro de la decoración. Las formas poligonales de aristas vivas dan paso a otras formas más curvas y redondeadas que se complementan con motivos florales más complejos en cuanto a su ejecución, incluyendo los motivos en forma de ramillete. Siguen apareciendo motivos de frutos que nacen de las hojas de las flores. Las cenefas que rematan las túnicas aparecen en oro pulido punzonados presentando diseños de cintas ondulantes con elipses. [12]

En este conjunto de obras destaca que las decoraciones de los mantos en su cara externa emplean el método 1, aportando una gran luminosidad al conjunto y priorizando la mirada hacia esas zonas, frente a las túnicas. Los motivos decorativos se componen principalmente de formas florales, vegetales, o combinadas entre sí,

9 Las esculturas que constituyen este grupo son: San José de la Iglesia Convento de Santa Eufemia (106ICSER01E1), San José de la Iglesia Convento de la Trinidad (107-ICTR02E1), San José de la Iglesia Convento de Capuchinos (109-ICpR01E1), San José de la Iglesia Colegial de San Sebastián (112-ICSSR03E1A) y San José de la Iglesia Convento Nuestra Señora de Loreto (124-INSLR01E1).

10 Las esculturas que constituyen este grupo son: San José de la Iglesia Convento Nuestra Señora de los Remedios (108-ICNSRR03E1B), San José de la Iglesia Convento de la Encarnación (111-ICER02E1). 


\begin{tabular}{|c|c|}
\hline 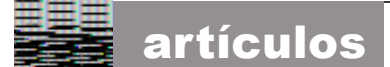 & La Policromía de Andrés de Carvajal \\
\hline
\end{tabular}

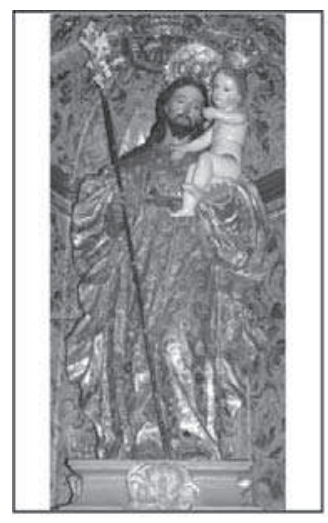

108-ICNSRR03E1B

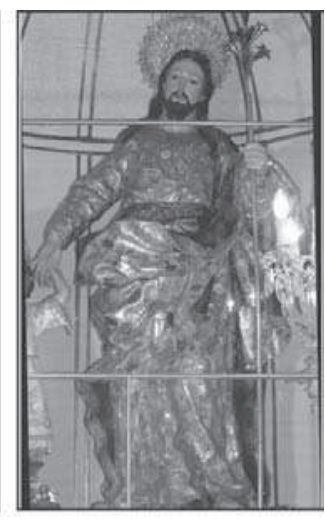

111-ICER02E1

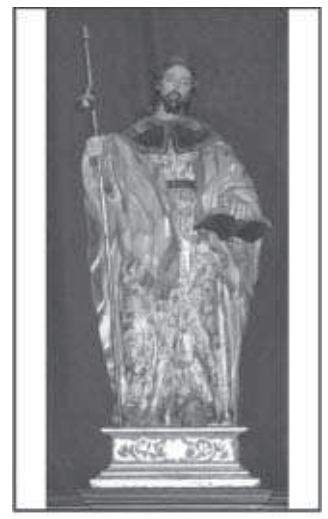

40-ISAR01E1

realizadas a pincel todas ellas. El diseño de los motivos consiste en una estructura base en forma de tres tallos unidos por un punto del que nacen flores, hojas y frutos. Las esculturas de las Iglesias de la Trinidad y la Encarnación, incorporan motivos de guirnalda y motivos de red, y ramillete respectivamente, todos ellos realizados a pincel. En estas policromías, el manto carece de cenefa, continuando el oro hasta los bordes sin ningún tipo de ornamentación final.

A diferencia de la homogeneidad de procedimiento técnico empleado para los mantos en su cara externa, los mantos en su cara interna, no presentan una unidad concreta respecto a su técnica. Aparecen policromados tanto en color verde con (106-ICSER01E1) y sin decoración (109-ICpR01E1 y 112-ICSSR03E1A); policromados en ocre sin decoración (107-ICTR02E1); corlados en verde con decoración (111-ICER02E1); o sin decoración (124-INSLR01E1), y empleando el método 1 (108-ICNSRR03E1B).

[13] La escultura de Santiago (40-ISAR01E1) va ataviada con túnica y capa, presenta el método 3 en la túnica que es de color blanco, y ningún tipo de decoración en la capa, a excepción de la cenefa de oro que cubre todo el perímetro. La túnica está decorada con esgrafiados rayados horizontales sobre blanco en el fondo. La decoración está compuesta por motivos de naturaleza floral y vegetal a pincel, y en reserva de oro que se disponen de forma ordenada alrededor de los motivos dorados en forma de lazos con aristas vivas y silueteadas a pincel. Se remata tanto el borde del manto como de la túnica con una cenefa con diseños de flores en oro pulido punzonado. 


\section{SANTOS: SEGUNDO MODELO ICONOGRÁFICO.}

El segundo grupo iconográfico que mayoritariamente representa la obra de Carvajal, es un conjunto de nueve esculturas ${ }^{11}$, donde se representan imágenes masculinas de santos, dos ángeles abanderados y excepcionalmente una representación de Santa Teresa (49-IBR03E1B). Este conjunto de obras se caracterizan por ser imágenes de orden secundario, ya que la mayor parte de ellas se ubican en los laterales de altares o retablos, como parte integrante del discurso iconográfico pero sin ser las protagonistas del mismo, exceptuando las figuras de San Francisco (79-ICSDR03E1A) y Santo Domingo (78-ICSDR03E1B), que constituyen las imágenes centrales del retablo Mayor de la Iglesia Convento de Santo Domingo, y como tal presentan motivos decorativos a pincel más trabajados que en el resto de las esculturas. [14] [15]

La mayor parte de estas esculturas están consideradas por los investigadores como obras de taller, de escasa calidad artística en cuanto a policromía se refiere. Ello se refleja directamente en el aspecto formal de las policromías, por otro lado muy similar entre ellas, en el que los colores, motivos y procedimientos se repiten. La gama cromática que emplean de escaso colorido, se centra en los tonos blanco, negro, gris y marrón, con algunas excepciones de colores más intensos como rojos y azules. Al emplear como procedimiento de ejecución el método 2, las policromías presentan un aspecto apagado como consecuencia directa de la inexistencia de una capa intermedia de oro entre el bol y la capa de color de fondo de la policromía. Por el contrario, destacan los motivos decorativos en reserva de oro, ya que el brillo de estas zonas contrasta fuertemente con la austeridad del color mate de fondo, y los motivos a pincel quedan relegados a un segundo plano, confundiéndose a cierta distancia con el fondo de las policromías.

Los motivos decorativos de las vestimentas, se reiteran de unas obras a otras, son en general de trazado sencillo y repetitivo, con formas poligonales de aristas vivas y frutos característicos del autor, o bien, de naturaleza floral y vegetal, o combinadas. Las cenefas que rematan las indumentarias son en su totalidad doradas y con decoración en forma de zig-zag con palmetas o flores de lis.

11 Las esculturas que constituyen este grupo son: San Antonio Abad de la Iglesia de Belén (48-IBR03E1A), Santa Teresa de la Iglesia de Belén (49-IBR03E1B), San Cayetano de la Iglesia Convento de San Agustín (68-ICSAR02E2), San Rafael de la Iglesia Convento San Sebastián (71-ICSSR03E1B), San Joaquín de la Iglesia Convento San Sebastián (75-ICSSR07E1A), San Cristóbal de la Iglesia Convento San Sebastián (76ICSSR07E1C), Ángeles Abanderados de la Iglesia Convento San Sebastián (77-ICSSR07E2A-C), y Santo Domingo de la Iglesia Convento Santo Domingo (80-ICSDR03E1B). 


\begin{tabular}{|c|c|}
\hline 警琶 artículos & La Policromía de Andrés de Carvajal \\
\hline
\end{tabular}

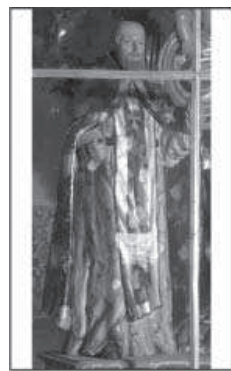

48-IBR03E1A

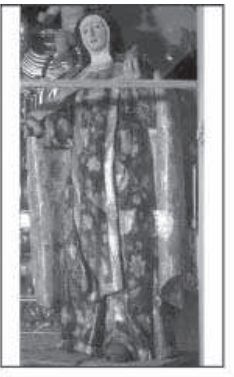

49-IBR03E1B

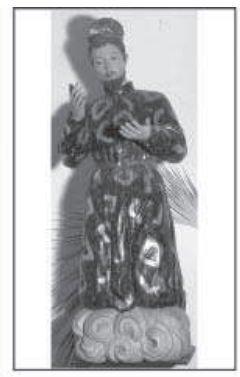

68-ICSAR02E2

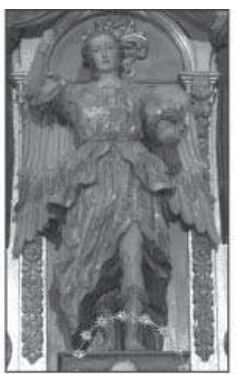

71-ICSSR03E1B

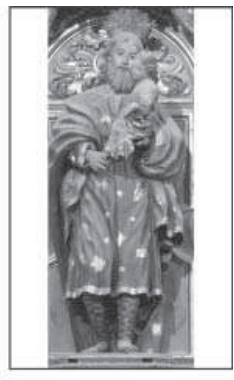

75-ICSSR07E1A

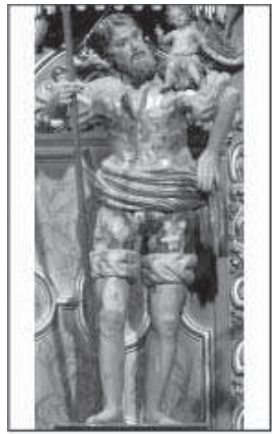

76-ICSSR07E1C

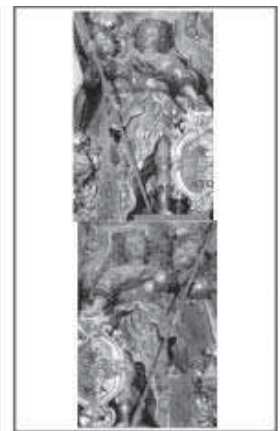

77-ICSSR07E2A-C

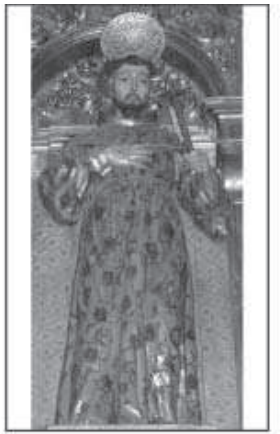

79-ICSDR03E1A

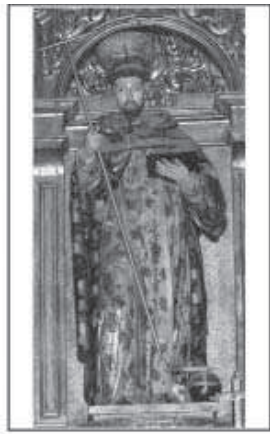

78-ICSDR03E1B

Virgen y Santa Eufemia: tercer modelo iconográfico.

La imagen femenina en la obra de Carvajal se manifiesta en la representación de la Virgen o de Santa Eufemia, patrona de la ciudad de Antequera. Este grupo iconográfico es muy reducido, ciñéndose solamente a cuatro esculturas, dos de cada. Todas ellas van ataviadas con túnica de color oro o marrón (solamente la virgen Inmaculada de la Iglesia del Convento de San Agustín), y manto azul para la virgen y rojo para las santas. [16]

En las túnicas el procedimiento de ejecución que ha empleado el artista es el método 1, destacando como las zonas más relevantes y visibles de conjunto polícromo de cada obra. Sin embargo, aunque la escultura de la Inmaculada de San Agustín presenta los mismos aspectos formales, muestra una variante muy curiosa, 


\begin{tabular}{|c|c|}
\hline 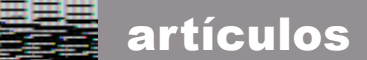 & Beatriz Prado Campos \\
\hline
\end{tabular}

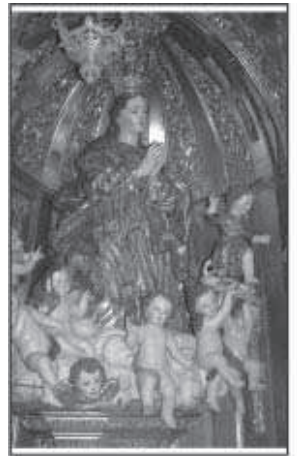

57-ICNSRR02E1B

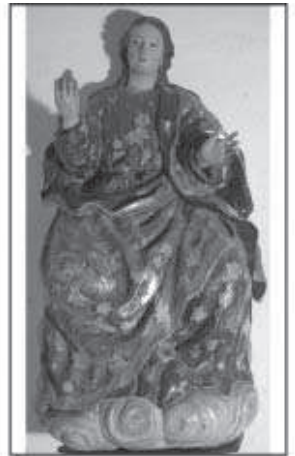

110-ICSAR02E1

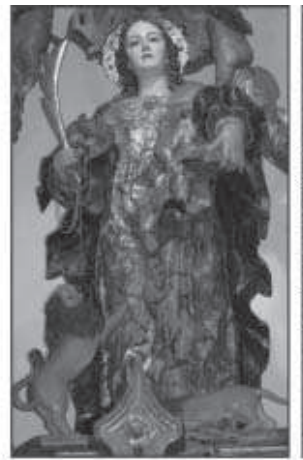

43-ICSER03E1B

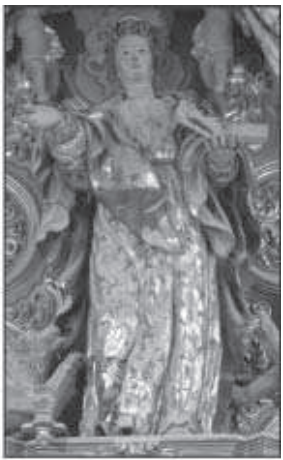

113-ICSSR07E2B

ya que el procedimiento y decoración es el mismo que en las otras obras, pero con la diferencia de que no se incluye la capa de oro pulido, siendo esta, sustituida por una capa de color marrón directamente aplicada sobre el bol. Los motivos decorativos son de naturaleza floral y vegetal en las cuatro obras. Las esculturas de la Virgen del Refugio y Santa Eufemia (43-ICSER03E1B), alternan motivos en forma de lazos ondulantes que se distribuyen por toda la superficie policroma y de la que nacen el resto de los motivos. Las cenefas son inexistentes en este tipo de método, como ya se ha apuntado anteriormente.

La decoración de los mantos en su cara externa se realiza aplicando los métodos 2 y 3 .

- El método 2, empleado en las esculturas que representan a la virgen ${ }^{12}$ : presentando esta zona polícroma un aspecto más mate respecto a las túnicas debido a su policromías azul aplicada sobre la capa de bol, sin intermediar una base de oro. Los motivos decorativos alternan zonas en reserva de oro y tratadas a pincel, representado elementos florales y formas poligonales de aristas vivas. Se rematan los mantos con cenefas en forma de cintas en zig-zag triples, con flores de lis.

- El método 3, empleado en las esculturas que representan a Santa Eufemia $^{13}$ : el fondo dorado y policromado en rojo son esgrafiados a base de esgrafiados rayados horizontales. Los motivos decorativos con formas florales ricas en su diseño, se distribuyen de forma ordenada pero sin ocupar todo el espacio

12 Las esculturas que constituyen este grupo son: Virgen del Refugio de la Iglesia Convento de Nuestra Señora de los Remedios (57-ICNSRR02E1B) e Inmaculada de la Iglesia Convento de San Agustín (110ICSAR02E1).

13 Las esculturas que constituyen este grupo son: Santa Eufemia de Iglesia Convento de Santa Eufemia (43ICSER03E1B) y Santa Eufemia del Iglesia Convento de San Sebastián (113-ICSSR07E2B). 
polícromo, predominando visualmente los motivos a pincel frente a los motivos en reserva de oro punzonados. Se rematan los mantos con cenefas en oro punzonado en forma de cintas en zig-zag triples con palmetas.

La decoración del envés de los mantos en su cara interna no es homogénea, presentando corladuras verdes sin decoración (43-ICSER03E1B y 113ICSSR07E2B), corladura roja sin decoración (110-ICSAR02E1) y policromado en rojo con decoración esgrafiada en forma de moteados y motivos decorativos en reserva de oro (57-ICNSRR02E1B). 
